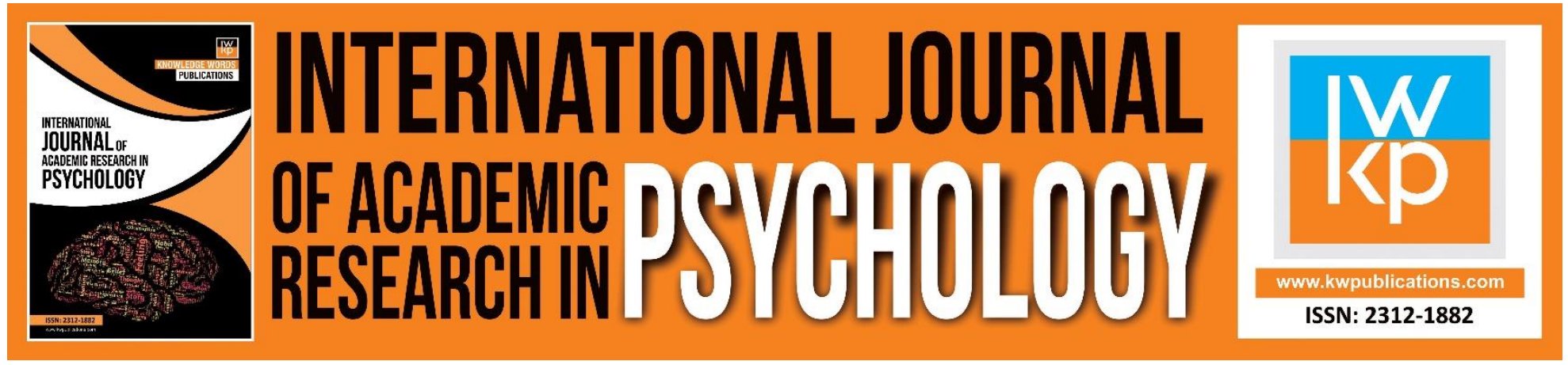

\title{
The Impact of Instagram Use on Body Image Concerns among Iranian University Female Students: A Phenomenological Approach
}

Seyed Mahdi Sharifi, Afshin Omidi, Bita Marzban

To Link this Article: http://dx.doi.org/10.46886/IJARP/v3-i1/2280

DOI:10.46886/IJARP/v3-i1/2280

Received: 03 March 2016, Revised: 07 May 2016, Accepted: 10 June 2016

Published Online: 27 June 2016

In-Text Citation: (Sharifi et al., 2016)

To Cite this Article: Sharifi, S. M., Omidi, A., \& Marzban, B. (2016). The Impact of Instagram Use on Body Image Concerns among Iranian University Female Students: A Phenomenological Approach. International Journal of Academic Research in Psychology. 3(1), 26-36.

\section{Copyright: (c) 2016 The Author(s)}

Published by Knowledge Words Publications (www.kwpublications.com)

This article is published under the Creative Commons Attribution (CC BY 4.0) license. Anyone may reproduce, distribute, translate and create derivative works of this article (for both commercial and non-commercial purposes), subject to full attribution to the original publication and authors. The full terms of this license may be seen at: http://creativecommons.org/licences/by/4.0/legalcode

Vol. 3, No. 1, 2016, Pg. 26 - 36

https://kwpublications.com/journals/journaldetail/IJARP

JOURNAL HOMEPAGE

Full Terms \& Conditions of access and use can be found at https://kwpublications.com/pages/detail/publication-ethics 


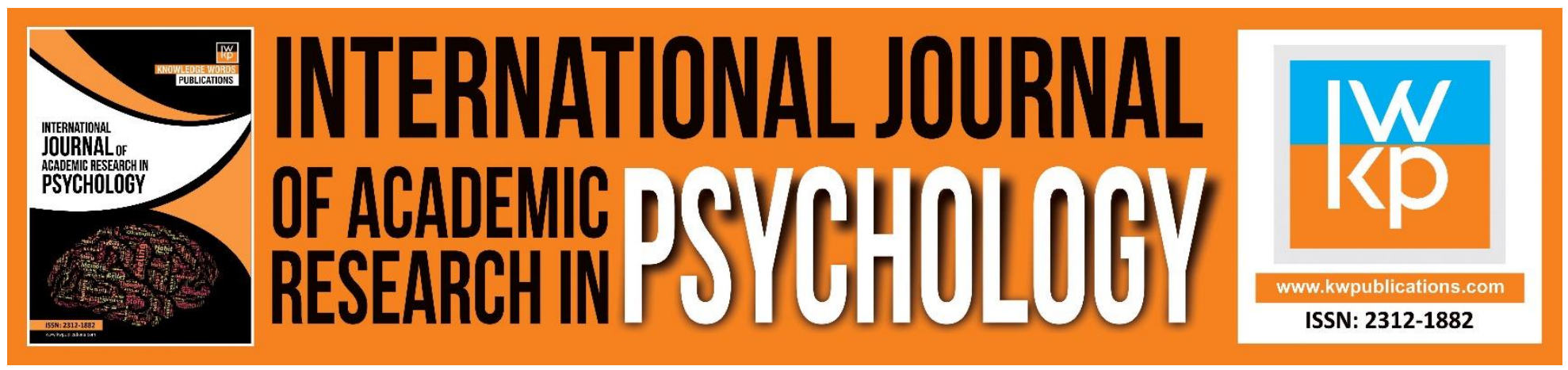

\title{
The Impact of Instagram Use on Body Image Concerns among Iranian University Female Students: A Phenomenological Approach
}

\author{
Seyed Mahdi Sharifi, Afshin Omidi \\ Department of Media Management, University of Tehran, Tehran, Iran. \\ Email: aomidi@ut.ac.ir \\ Bita Marzban \\ Department of Media Management, University of Tehran, Tehran, Iran.
}

\begin{abstract}
Body image is how we mentally "see" our bodies and has both perceptual and attitudinal components and body image dissatisfaction is acknowledged as a pervasive problem experienced by a large proportion of society. The main scoping of this present work is to investigate the underlying processes between Instagram use and body image concerns. We used a qualitative study with phenomenological approach in this study and purposive sampling to recruit female students $(n=12)$, were aged between 24 and 34. participants were recruited from university of Tehran, Tehran, Iran. Based upon the findings of this article, the studies show that there are three key themes around body image concerns among Iranian female students. These include: (a) changes in body appearance, (b) health and Beauty and (c) Instagram effects. Taken all, it can be concluded that the there is an essential need to promoting critically thinking among Iranian female students.
\end{abstract}

Keywords: Body Image, Instagram, Phenomenological Approach, Iran.

\section{Introduction}

Body image is defined as a multidimensional self-attitude toward one's body, particularly its size, shape, and aesthetics (Holt \& Lyness, 2007). These perceptions, thoughts, feelings, and behaviors can be positive or negative in nature and affect many aspects of psychosocial well-being and quality-oflife (Bailey, Gammage, van Ingen, \& Ditor, 2015). Body image is how we mentally "see" our bodies and has both perceptual and attitudinal components (Findler, Taubman-Ben-Ari, \& Jacob, 2007) and body image dissatisfaction is acknowledged as a pervasive problem experienced by a large proportion of society (Dohnt \& Tiggemann, 2006). Concerned with the potential negative effects, much scholarly research, as well as public speculations, has been devoted to investigating the impact of thin-ideal 
body image exposure on individuals' eating disorder attitudes and behaviors (Wang, 2010). Body image is part of the self-state of one's physical appearance. Thus, individuals may experience negative emotional feelings when they perceive discrepancies between their ideal-body, ought-body, and actual-body image (Kim \& Aubrey, 2015). Although the literature on the prevalence of body image concerns is increasing, researchers have yet to systematically explore the relationships between body image and broad aspects of young people's lives, such as emotional and interpersonal functioning (Davison \& McCabe, 2006).

Body image issues are of global relevance and importance because abundant evidence has shown that women suffer from body image dissatisfaction in numerous countries and regions around the world (Zhang, 2012). Negative body image in particular is now widely recognized as an important public health concern because its high prevalence worldwide (Swami \& Knowles, 2014). Negative body image is a risk factor for numerous unhealthy behaviors including fasting, self-induced vomiting, laxative misuse, and excessive exercise (Alleva, Martijn, Van Breukelen, Jansen, \& Karos, 2015). A historical perspective of the media's portrayal of the ideal body size and shape demonstrates change over the last century (Lawrie et al., 2006) and media exposure in our daily lives illustrates how greatly our culture values appearance (Wagenbach, 2004). There is increasing pressure during adolescence for males and females to desire a body shape that conforms to the "ideal", i.e. a thin shape for women and a lean, muscular shape for men. These perceived ideal body shapes are reinforced by the mass media and popular cultural icons. Internalization of body ideals that are perpetuated by the media can be a strong influence on body dissatisfaction, especially among females (Hawkins et al., 2004; Khan et al., 2011; Sharp \& Tiggemann, 2016). As a result, females may have negative body image and experience serious eating disturbances and psychological problems (Frederick et. al., 2016; Schleien \& Bardone-Cone, 2016). For better understanding the influence of media on negative body image perception and subsequent negative health behaviors (e.g., disordered eating, substance abuse, and surgical fat reduction), it is essential to analyze the processes and examine how thin-ideal media use is associated with body image disturbance (Kim \& Aubrey, 2015).

Increasingly, however, researchers have begun exploring media effects on body images of young women from different racial and ethnic groups (Perloff, 2014). In many ways, the research on media effects on body image has followed the course of any new field of inquiry in psychology. The earliest studies tend to be straight-forward analyses, interviews, or simple surveys that seek to identify, document, or describe a phenomenon (Tiggemann, 2014). Media researchers have focused on illustrating the direct effects of media use on negative body image and eating disorders over the past two decades. Most studies have agreed with the idea that thin-ideal media use is one of the primary sociocultural factors that directly affects negative body image, which leads to negative behavioral outcomes such as disordered eating (Dohnt \& Tiggemann, 2006; Kennett, Humphreys, \& Schultz, 2011; Kim \& Aubrey, 2015; López-Guimerà, Levine, Sánchez-carracedo, \& Fauquet, 2010; RabakWagener, Eickhoff-Shemek, \& Kelly-Vance, 1998). Decades of research has documented the negative impact that traditional media (such as magazines and television) has on people's body image concerns. However, given the increasing popularity of social media, researchers are beginning to investigate the possible consequences that these new media formats have on body image (Fardouly \& Vartanian, 2016). Images of idealized bodies and how individuals consume them has been extensively studied in terms of traditional media such as magazines, television, advertising, etc. Little 
published research to date, however, has examined whether and how social media use, specifically, may influence perceptions of physical ideals (Andsager, 2014).

In addition to traditional media, there has been an explosive increase in social media use, particularly among young people. Social media refers to "a group of Internet-based applications that build on the ideological and technological foundations of Web 2.0, and that allow the creation and exchange of user-generated content"'(Lee, Lee, Choi, Kim, \& Han, 2014). One study, identified participants who spent time on Facebook reported being in a more negative mood than those who spent time on the control website (Fardouly, Diedrichs, Vartanian, \& Halliwell, 2015).

We selected Instagram based on its popularity among Iranian people. Although some effects of social media use may be universal, the degree to which individuals are affected by social media use may vary across cultures (Lee et al., 2014). Indeed, studying positive body image is "essential to the future of the field" (Tylka \& lannantuono, 2016). The main scoping of this present work is to investigate the underlying processes between Instagram use and body image concerns and contribute to the emerging literature on the relationship between social media and the psychological well-being of Iranian university female students. To the researchers' knowledge, this is one of the first studies exploring effects of social media on body image concerns among Iranian female students through a qualitative method.

\section{Method}

\section{Research Design}

A qualitative study with phenomenological approach was employed in this study. it contributes to an understanding of the human condition in different contexts and of a perceived situation (Bengtsson, 2016). In terms of phenomenology as methodological orientation there are different approaches developed by different researchers. These all describe steps that must be taken in a phenomenological study, but they also agree that doing phenomenology is not possible by following a step-wise procedure. More important is the adoption and practice of a certain attitude of sensitivity to the phenomenon under study, the lived experience of the research participants, and the way their experiences are expressed through actions, speech and silences. This attitude must be sustained and cultivated throughout the research process (Standal \& Engelsrud, 2013) For the phenomenological methods, focus is on rich description of some aspects of experience, described through language (Davidsen, 2016). Phenomenology is not just a research method; it is a philosophy in origin and has epistemological and methodological implications for empirical research (Eberle, 2015). The primary objective of phenomenological research is to undertake the "meaningful concrete relations implicit in the original description of experience in the context of a particular situation" (Carter \& Carter, 2010).

\section{Participants}

We used purposive sampling to recruit female students ( $n=12)$, were aged between 24 and 34 . participants were recruited from university of Tehran, Tehran, Iran. During the recruitment, some snowball sampling naturally occurred. We did not encounter any major ethical dilemmas throughout the research process. Participants signed a consent form prior to a face-to-face interview which was audio recorded. All names are presented as pseudonyms to ensure their privacy will be fully 
INTERNATIONAL JOURNAL OF ACADEMIC RESEARCH IN PSYCHOLOGY

Vol. 3, No. 1, 2016, E-ISSN: 2312-1882 @ 2016 KWP

preserved. They were assured that they could withdraw from the study at any time without recrimination.

\section{Procedure}

A total of 12 interviews were conducted with female students. Face-to-face semi-structured interviews were undertaken. Data collection and analysis were conducted simultaneously. Data collection continued until no new issues emerged. Each participant interviewed chose a time and location that was convenient for them. Interviews lasted between 45 and 60 minutes and were audio recorded and also transcribed verbatim. Many themes were coded using the constant comparative method. Constant comparison was used as a way of maintaining a connection between the codes and a constant re-examining of the text to ensure consistency of the application of that particular code and to ensure that codes and categories developed to fit the data (Abdu, Stenner, \& Vydelingum, 2015). The participants were interviewed individually by the researcher at a private location of their choice. Some examples of the questions asked were "What do you think about Instagram's representation of the female body?" "Do you know anyone in real life who has had cosmetic surgery" "What do you think about it?" "Do your Instagram tend to glamorise a specific body type? Why does it matter?" and "How do you want to connect the three concepts, health, female body and beauty?" When no new properties of the categories could be identified, the data were considered to be saturated.

For the first step, we identified all data that were related to pre-classified patterns. The patterns include: (1) increasing confidence, (2) attitude toward cosmetic surgery, (3) achieving health, (4) attracting attention, (5) social comparisons, (6) the nature of beauty, (7) health risk for beauty, (8) Instagram opportunities and (9) Instagram threats. In the next step, we aimed to combine and catalogue related patterns into themes according to the table1. Three main themes emerged during the research that each of them individually explained.

Table1. Key themes in this study

\begin{tabular}{|l|l|}
\hline Conceptual codes & Themes \\
\hline Increasing confidence & \multirow{2}{*}{ Changes in body appearance } \\
\cline { 1 - 1 } Attitude toward cosmetic surgery & \\
\cline { 1 - 1 } Achieving health & \multirow{2}{*}{ Health and Beauty } \\
\hline Attracting attention & Instagram effects \\
\hline Social comparison & \\
\hline Health risk for beauty & \\
\hline Instagram opportunities & \\
\hline Instagram threats &
\end{tabular}


INTERNATIONAL JOURNAL OF ACADEMIC RESEARCH IN PSYCHOLOGY

Vol. 3, No. 1, 2016, E-ISSN: 2312-1882 @ 2016 KWP

\section{Results}

\section{Changes in Body Appearance}

This study showed that increasing confidence and attracting attention were one of the main motivations of the Iranian participants in order to change their body appearance.

Sima said, "I had experience in cosmetic surgery and diet... because of the increasing my confidence." Also Roya pointed out that, "Anyone who has low confidence, will try to have a better face." Lili noted that "I feel that people through a diet and cosmetic surgery can achieve the desired confidence." Also Mary said, "In any case people who are looking for beauty, Want to attract attention" and "Women are trying to show off themselves to attract attention" (Ziba).

On the other side, in this study, social comparison was an important factor for change body appearance among Iranian female students. Of course, such comparisons can also have positive results and negative results. For example Sara said, "The weight of my most intimate friend was exactly half my weight. This was the motivation for me to exercise."

It is necessary here to point out the attitudes towards cosmetic surgery among the participants. "I partly agree with cosmetic surgery that the person can increase her confidence and through it, the success achieved, but may lose their attractiveness through indulgence" (Sima).

However, some participants were not deemed in any way to do it right. "I absolutely disagree with this work (cosmetic surgery)" (Lida). Mary had a more critical perspective around cosmetic surgery. She pointed out that, "Who can not tolerate her face, will not tolerate another's face."

Fortunately, some participants change their body appearance in order to achieve health. Lida said, "I was motivated to diet for the future... maybe now; the extra weight did not cause me trouble, but if I want to have children in the future, extra weight will be a problem for me." Also she said, "Beauty to me is important, but not because draw attention... I think that ten years coming I would love to run in the park."

\section{Health and Beauty}

One of the most important factors in body image concerns was participants' attitudes toward the nature of beauty.

Roya said, "if someone speaks well, be regular or has a good character...thete exist no reason to have a beautiful face or body." She also pointed out that, "women who are natural, they are more attractive for me rather than have cosmetic surgery."

Sepid said, "when you happy and healthy then you are beautiful." Lida noted that, "I always see the picture of a woman that I love her...she does not makeup...she is herself...this made me very attracts" and "actually beauty is not in the form of face and body...I think being healthy is enough for beauty." Dangerous issue is that some people in order to achieve the desired beauty doing high-risk behaviors. Marjan said, "A woman who for her, the cosmetic aspects are very important and follow it, Even if her health were be at risk, she will not miss a thing." However, for some people, health is the first priority. "Health is the most important thing in life" (darya).

\section{Instagram Effects}

Instagram has exploded over the past few years with the development of smartphone technology, allowing Instagram users to post pictures with edited effects, from their supported smartphone to their Instagram account (Sanvenero, 2013). Each day, many millions of images are posted online 
through social media. Some 55 million of them alone are shared daily through Instagram (Thornton, 2014). Instagram users are able to take, process and upload images or short videos via their mobile phones (Olive, 2015). However, visual platforms such as Instagram are becoming increasingly popular, with some industry analysts positing that Instagram is the fastest growing social media platform (Smith \& Sanderson, 2015).

Widely, Iranian people use Instagram, and this has caused people to have more attention to photography. Mina said, "Wherever I go I want to take a picture and put in Instagram and be seen by others and to be encouraged."

Many women are greatly affected by the images of Instagram. This could be threatened because sometimes encouraged risky behavior. Tina said, "In fact, the reason that I went to solariums, was Instagram's fashions. I felt that I can be like them but it did not."

Sometimes, social pressure on Instagram changes the nature of beauty for Iranian people and encourages a certain type of appearance. Roya pointed out, "On Instagram when you do a lot of cosmetic surgery and tattoos, you can be pretty and attractive. But behind of those photos is not a healthy personality." Also she said, "If a famous girl be ugly, then all want to be like her."

Many participants believe that Instagram's impact is visible in the real world. Sociocultural theories posit that dissatisfaction with one's body can be caused by ideals constructed by society and disseminated via various media (Cranney, 2015).

Sara noted, "Not only in Instagram but also on the street you can see that all people look like each other."

Despite the negative effects of Instagram, for some people there is an opportunity to strengthen their good behavior. Lili said, "I build a public page on Instagram to my lose weight. During my diet, I put my photos on Instagram. I was very influential on opinions of people. They gave me positive energy. My motivation increased."

\section{Conclusion}

Media that depict thin women have a strong sociocultural impact by constructing and reinforcing social standards based on thin ideals (Kim, 2014). Correlational, cultural, and experimental evidence indicates that there is a link between exposure to media depicting images representative of the sociocultural ideals of attractiveness and body dissatisfaction and eating (Watson \& Vaughn, 2006). The Perloff's model focuses on specific content that can appear on social media and the Internet, such as on Thin-aspiration, the umbrella term for a variety of thinness-inspiring Internet-based blogs and images, and on Web sites that specifically promote eating disorders like anorexia and bulimia. Facebook, Instagram, and Pinterest are social media formats that allow for the creation and exchange of messages on particular body image-related content, exemplified by Thin-aspiration blogs and proeating disorder material (Perloff, 2014). Perloff (2014) attempts to broaden the theoretical discussion regarding the effects of media on women's body image concerns by extending it to social media (Prieler \& Choi, 2014).

Several researchers investigated the role of social comparison in processing thin media images and how social comparison may influence body image disturbance (Fardouly et al., 2015; Han, 2003). Social comparison theory, originally formulated by Festinger (1954), refers to people's tendency to compare themselves to others with respect to certain attributes, especially when the characteristics (e.g., beauty or sexiness) are important and the relevant standards or criteria for evaluation are 
ambiguous sociocultural comparison theory is the perspective most often used, as it operates on the key mechanisms involved in the relationship between body image and media exposure (LópezGuimerà et al., 2010). Upward comparison with the thin media characters may function as an opportunity of self-evaluation, and such evaluation may be associated with negative body image of female viewers and with pressure of having a body like the thin media characters. Thus, the more female viewers make upward comparison with thin media characters, the more likely they have body image dissatisfaction (Han, 2003).

Analysis of themes in the narratives revealed that participants have different purposes for weight loss; the differences in goals for dieting uncovered culturally situated meanings of dieting behaviors (Kim, 2014).

Based upon the findings of this article, the studies show that there are three key themes around body image concerns among Iranian female students. These include: (1) changes in body appearance, (2) health and Beauty (3) Instagram effects. Taken all, it can be concluded that the there is an essential need to promoting critically thinking among Iranian female students.

Media literacy, particularly high levels of critical thinking, mitigated the negative effects of trait thinideal internalization and trait upward appearance comparison on body satisfaction outcomes. These findings provide evidence for the role of media literacy as a protective factor against the negative effects on body satisfaction of exposure to thinideal media images, and also provide evidence to support the development and implementation of media literacybased body image interventions (McLean, Paxton, \& Wertheim, 2016).

It would be worthwhile to explore how can media politics help Iranian female students to decrease negative effects of Instagram on body image concern among them.

\section{References}

Abdu, L., Stenner, K., \& Vydelingum, V. (2015). Exploring the health visiting service from the view of South Asian clients in England: a grounded theory study. Health \& Social Care in the Community, n/a-n/a. http://doi.org/10.1111/hsc.12233

Alleva, J. M., Martijn, C., Van Breukelen, G. J. P., Jansen, A., \& Karos, K. (2015). Expand Your Horizon: A programme that improves body image and reduces self-objectification by training women to focus on body functionality. Body Image, 15, 81-89. http://doi.org/10.1016/j.bodyim.2015.07.001.

Andsager, J. L. (2014). Research Directions in Social Media and Body Image. Sex Roles, 71(11-12), 407-413. http://doi.org/10.1007/s11199-014-0430-4.

Bailey, K. A., Gammage, K. L., van Ingen, C., \& Ditor, D. S. (2015). "It's all about acceptance": A qualitative study exploring a model of positive body image for people with spinal cord injury. Body Image, 15, 24-34. http://doi.org/10.1016/j.bodyim.2015.04.010.

Bengtsson, M. (2016). How to plan and perform a qualitative study using content analysis. NursingPlus Open, 2, 8-14. http://doi.org/10.1016/j.npls.2016.01.001.

Carter, P., \& Carter, D. (2010). Emotional risk-taking in marital relationships: A phenomenological approach. Journal of Couple \& Relationship Therapy, 9(4), 327-343. http://doi.org/10.1080/15332691.2010.515533.

Cranney, S. (2015). Internet Pornography use and Sexual Body Image in a Dutch Sample. International Journal of Sexual Health, 27(3), 316-323. 
INTERNATIONAL JOURNAL OF ACADEMIC RESEARCH IN PSYCHOLOGY

Vol. 3, No. 1, 2016, E-ISSN: 2312-1882 @ 2016 KWP

http://doi.org/10.1080/19317611.2014.999967

Davidsen, A. S. (2016). Qualitative Research in Psychology Phenomenological Approaches in Psychology and Health Sciences Phenomenological Approaches in Psychology, 0887(March). http://doi.org/10.1080/14780887.2011.608466.

Davison, T. E., \& McCabe, M. P. (2006). Adolescent body image and psychosocial functioning. The Journal of Social Psychology, 146(1), 15-30. http://doi.org/10.3200/SOCP.146.1.15-30

Dohnt, H. K., \& Tiggemann, M. (2006). Body image concerns in young girls: The role of peers and media prior to adolescence. Journal of Youth and Adolescence, 35(2), 141-151. http://doi.org/10.1007/s10964-005-9020-7.

Eberle, T. S. (2015). Exploring Another's Subjective Life-World : A Phenomenological Approach. http://doi.org/10.1177/0891241615587383.

Fardouly, J., Diedrichs, P. C., Vartanian, L. R., \& Halliwell, E. (2015). Social comparisons on social media: the impact of Facebook on young women's body image concerns and mood. Body Image, 13, 38-45. http://doi.org/10.1016/j.bodyim.2014.12.002.

Fardouly, J., \& Vartanian, L. R. (2016). Social Media and Body Image Concerns: Current Research and Future Directions. Current Opinion in Psychology, 9, 1-5.

Findler, L., Taubman-Ben-Ari, O., \& Jacob, K. (2007). Internal and external contributors to maternal mental health and marital adaptation one year after birth: comparisons of mothers of preterm and full-term twins. Women \& Health, 46(4), 39-60. http://doi.org/10.1300/J013v46n04.

Frederick, D. A., Kelly, M. C., Latner, J. D., Sandhu, G., \& Tsong, Y. (2016). Body image and face image in Asian American and white women: Examining associations with surveillance, construal of self, perfectionism, and sociocultural pressures. Body Image, 16, 113-125. http://doi.org/10.1016/j.bodyim.2015.12.002.

Han, M. (2003). Body image dissatisfaction and eating disturbance among Korean college female students: Relationships to media exposure, upward comparison, and perceived reality. Communication Studies, 54(1), 65-78. http://doi.org/10.1080/10510970309363266

Hawkins, N., Richards, P. S., Granley, H. Mac, \& Stein, D. M. (2004). The impact of exposure to the thin-ideal media image on women. Eating Disorders, 12(1), 35-50. http://doi.org/10.1080/10640260490267751.

Holt, A., \& Lyness, K. P. (2007). Body image and sexual satisfaction: Implications for couple therapy. Journal of Couple \& Relationship Therapy, 6(3), 45-68. http://doi.org/10.1300/J398v06n03

Kennett, D. J., Humphreys, T. P., \& Schultz, K. E. (2011). Sexual resourcefulness and the impact of family, sex education, media and peers. Sex Education, 12(3), 1-18. http://doi.org/10.1080/14681811.2011.615624.

Khan, A. N., Khalid, S., Khan, H. I., \& Jabeen, M. (2011). Impact of today's media on university student's body image in Pakistan: a conservative, developing country's perspective. BMC Public Health, 11(1), 379. http://doi.org/10.1186/1471-2458-11-379.

Kim, K. B. (2014). Narratives about the Media, Diet, and Body Image: A Cross-Cultural Comparison between Young Female Adults in the Midwestern United States and South Korea. Journal of Intercultural Communication Research, 43(4), 283-303. http://doi.org/10.1080/17475759.2014.952768.

Kim, K. B., \& Aubrey, J. S. (2015). A cross-cultural comparison of cognitive and affective mediators in 
INTERNATIONAL JOURNAL OF ACADEMIC RESEARCH IN PSYCHOLOGY

Vol. 3, No. 1, 2016, E-ISSN: 2312-1882 @ 2016 KWP

the relationship between media use and body image disturbance: focusing on US and Korean women. Asian Journal of Communication, 25(5), 507-524. http://doi.org/10.1080/01292986.2014.995681.

Lawrie, Z., Sullivan, E. a, Davies, P. S. W., \& Hill, R. J. (2006). Media influence on the body image of children and adolescents. Eating Disorders, 14(5), 355-64. http://doi.org/10.1080/10640260600952506.

Lee, H.-R., Lee, H. E., Choi, J., Kim, J. H., \& Han, H. L. (2014). Social Media Use, Body Image, and Psychological Well-Being: A Cross-Cultural Comparison of Korea and the United States. Journal of Health Communication, 19(12), 1343-1358. http://doi.org/10.1080/10810730.2014.904022.

Lopez-Guimera, G., Levine, M. P., Sanchez-carracedo, D., \& Fauquet, J. (2010). Influence of Mass Media on Body Image and Eating Disordered Attitudes and Behaviors in Females: A Review of Effects and Processes. Media Psychology, 13(4), 387-416. http://doi.org/10.1080/15213269.2010.525737.

McLean, S. A., Paxton, S. J., \& Wertheim, E. H. (2016). Does Media Literacy Mitigate Risk for Reduced Body Satisfaction Following Exposure to Thin-Ideal Media? Journal of Youth and Adolescence, 1-18. http://doi.org/10.1007/s10964-016-0440-3.

Olive, R. (2015). Reframing Surfing: Physical Culture in Online Spaces. Media International Australia, 155(1), 99-107. http://doi.org/10.1177/1329878X1515500112.

Perloff, R. M. (2014). Social Media Effects on Young Women's Body Image Concerns: Theoretical Perspectives and an Agenda for Research. Sex Roles, 71(11-12), 363-377. http://doi.org/10.1007/s11199-014-0384-6.

Prieler, M., \& Choi, J. (2014). Broadening the Scope of Social Media Effect Research on Body Image Concerns. Sex Roles, 71(11-12), 378-388. http://doi.org/10.1007/s11199-014-0406-4.

Rabak-Wagener, J., Eickhoff-Shemek, J., \& Kelly-Vance, L. (1998). The effect of media analysis on attitudes and behaviors regarding body image among college students. Journal of American College Health : J of ACH, 47(1), 29-35. http://doi.org/10.1080/07448489809595616.

Sanvenero, R. (2013). Social media and our misconceptions of the realities. Information \& Communications Technology Law, 22(2), 89-108. http://doi.org/10.1080/13600834.2013.805923.

Schleien, J. L., \& Bardone-Cone, A. M. (2016). Competitiveness as a moderator of the relation between appearance-related factors and disordered eating behaviors. Body Image, 17, 3037. http://doi.org/10.1016/j.bodyim.2016.01.009.

Sharp, G., \& Tiggemann, M. (2016). Educating women about normal female genital appearance variation. Body Image, 16, 70-78. http://doi.org/10.1016/j.bodyim.2015.11.006.

Smith, L. R., \& Sanderson, J. (2015). I'm Going to Instagram It! An Analysis of Athlete SelfPresentation on Instagram. Journal of Broadcasting \& Electronic Media, 59(2), 342-358. http://doi.org/10.1080/08838151.2015.1029125.

Standal, O`. F., \& Engelsrud, G. (2013). Researching embodiment in movement contexts: a phenomenological approach. Sport, Education and Society, 18(2), 154-166. http://doi.org/10.1080/13573322.2011.608944.

Swami, V., \& Knowles, V. (2014). Mental health literacy of negative body image: symptom recognition and beliefs about body image in a British community sample. International 
INTERNATIONAL JOURNAL OF ACADEMIC RESEARCH IN PSYCHOLOGY

Vol. 3, No. 1, 2016, E-ISSN: 2312-1882 @ 2016 KWP

Journal of Culture and Mental Health, 7(2), 199-215.

http://doi.org/10.1080/17542863.2013.769611.

Thornton, L.-J. (2014). The Photo Is Live at Applifam: An Instagram Community Grapples With How Images Should Be Used. Visual Communication Quarterly, 21(2), 72-82.

http://doi.org/10.1080/15551393.2014.928147.

Tiggemann, M. (2014). The Status of Media Effects on Body Image Research: Commentary on

Articles in the Themed Issue on Body Image and Media. Media Psychology, 17(2), 127-133. http://doi.org/10.1080/15213269.2014.891822.

Tylka, T. L., \& lannantuono, A. C. (2016). Perceiving beauty in all women: Psychometric evaluation of the Broad Conceptualization of Beauty Scale. Body Image, 17, 67-81. http://doi.org/10.1016/j.bodyim.2016.02.005.

Wagenbach, P. (2004). Lesbian body image and eating issues. Journal of Psychology \& Human Sexuality, 15(4), 205-227.

Wang, X. (2010). More Than Just Anorexia and Steroid Abuse: Effects of Media Exposure on Attitudes Toward Body Image and Self-Efficacy. Atlantic Journal of Communication, 18(1), 50-62. http://doi.org/10.1080/15456870903210089.

Watson, R., \& Vaughn, L. M. (2006). Limiting the Effects of the Media on Body Image: Does the Length of a Media Literacy Intervention Make a Difference? Eating Disorders, 14(5), 385400. http://doi.org/10.1080/10640260600952530.

Zhang, M. (2012). A Chinese beauty story: how college women in China negotiate beauty, body image, and mass media. Chinese Journal of Communication, 5(4), 437-454.

http://doi.org/10.1080/17544750.2012.723387. 